\title{
O ETHOS SANJOANENSE: TRADIÇÃO E MUDANÇA EM UMA "CIDADE PEQUENA"*
}

Márcio Caniello

A oposição entre estrutura e história é um dos elementos centrais do debate epistemológico na antropologia social moderna. Resultado da crítica aos modelos explicativos em larga medida conjecturais do evolucionismo, essa oposição foi um instrumento fundamental na reivindicação de uma heurística própria para a disciplina feita em 1949 por Lévi-Strauss (1975:15) ${ }^{1}$ que, depois, manteria a célebre polêmica em torno do assunto com Sartre (cf. Sartre 1960; Lévi-Strauss 1976 [1962]:280-ss.). Contudo, apesar de sua importância para a construção da identidade da antropologia, a polarização do debate em torno de categorias epistemológicas excludentes, de resto uma característica do "campo" das ciências sociais (cf. Alexander 1987), tem sido denunciada como infértil por vários autores, como J effrey Alexander (1990), Norbert Elias (1994:13-60), Anthony Giddens (1989) e M arshall Sahlins, que considera essas oposições "não apenas fenomenologicamente enganadoras, mas também analiticamente debilitantes" (Sahlins 1990:18). Estes autores defendem uma proposta alternativa: a construção de perspectivas analíticas fundamentadas em operações de síntese teórica.

Esta postura lançou nova luz sobre a questão das interpolações entre tradição e mudança na dinâmica dos sistemas sociais, motivação teórica de meus principais empreendimentos de pesquisa ${ }^{2}$, nos quais me dediquei a demonstrar que o "estilo" ou o "jeito de ser" de um povo - vale dizer, o signo e a essência da tradição cultural que define o indivíduo e sua sociedade (cf. DaM atta 1986:15) - reage ao fluxo histórico, equilibrando-se em uma dialética que, embora explicite mudanças, ressalta, sobretudo, permanências. Ou seja, na relação entre tendências de estabilidade estrutural e pressões modificadoras conjunturais, o "estilo" de um povo, o seu "jeito de ser", mantém a integridade modulando-se 3 no tempo, isto é, sintetizando tradição e mudança.

$\mathrm{Na}$ busca do refinamento dessa idéia, chegamos ao conceito de ethos, palavra antiga já usada por Homero (cf. Vergnières 1999:82-88) e 
A ristóteles (1973:267), que foi apropriada pelas ciências sociais primeiramente por Alfred Kroeber, que define ethos como um "aroma" que impregna a cultura como um todo (cf. Kroeber 1963 [1923]:101-102), concepção na mesma direção formulada por Geertz (1978 [1973]:143). No sentido que lhe dão esses autores, o conceito de ethos tem estreita identidade com a noção de Volksgeist (espírito de um povo), elemento central da filosofia da história de Hegel (1982 [1837]) (cf. Hyppolite 1983:19-20 e Inwood 1997:117-120), a qual prefigura a perspectiva de síntese que adoto nesta abordagem, na medida em que, para Hegel, o "espírito de um povo" estará sempre traspassado pelo "espírito do tempo" (Zeitgeist), que Ihe impõe limitações e constrangimentos, mas que a longo prazo poderá revelar dinamismos e mudanças, permanências e recorrências. Ou seja, o ethos guarda a marca da estrutura que conforma a tradição de um povo, seu "espírito", mas também comporta os influxos da ação dos sujeitos e das pressões conjunturais que interagem com essa estrutura em um determinado tempo histórico. Em uma palavra, considero o ethos como a matriz e a moeda dos processos sociais, pois é a resultante de uma dupla dialética entre a estrutura e a agência e entre a tradição e a mudança.

Neste artigo, indago como o " padrão pessoalizante de relações sociais" (cf. Caniello 1990a:46-47; 1993:12-16), arquetípico das chamadas "sociedades holistas ou tradicionais" 4 , âmago do ethos nacional brasileiro (cf. DaM atta 1983, passim; 1986:23-33; 1987, passim; 1993:125-149; Caniello 2001:344-356) e elemento estruturante da vida coletiva nas "cidades pequenas" (cf. Caniello 1993:60-70; Prado 1987:46-68) reage diante do "processo de individualização" (Elias 1994:102) provocado pela expansão do capitalismo e de seus valores dominantes (cf. Weber 1987). Meu objetivo é relativizar a concepção de que esse processo tenha redundado em uma decaída do estilo de vida tradicional da pequena cidade, como supõem, por exemplo, os autores dos clássicos “estudos de comunidade" 5 , mas também rejeitar a idéia de que a tradição se mantém incólume à passagem do tempo. Tomando como referência exatamente o período em que o Brasil passou a se incluir mais vigorosamente sob a "ordem social competitiva" (cf. Fernandes 1987:149, passim), irei reconstituir a trajetória do faccionalismo em São J oão Nepomuceno, pequena cidade de Minas Gerais, considerando-o como uma expressão proeminente do padrão pessoalizante de relações sociais e, portanto, como um indicador etnográfico eficaz das possíveis modulações do ethos local no trânsito histórico. 


\section{“Cidade pequena": unionismo e conflito}

As "cidades pequenas" são contextos em que a sociabilidade é largamente condicionada pela pessoalização porque os indivíduos estão incluídos em um ambiente social em que o al to grau de proximidade produz o que definimos em outra ocasião de "visibilidade inevitável" (Caniello e Soárez 1989:22): os sujeitos são reconhecidos uns pelos outros em virtude de suas marcas pessoais, e o mapeamento da rede que produz essas marcas é amplamente dominado pela coletividade. Isto é, a "cidade pequena" é um daqueles lugares onde "a pessoa não tem oportunidade, desejo ou possibilidade de ficar só" (Elias 1994:108) e, assim, as relações sociais são estruturadas em networks (cf. Landé 1977:xxxiii): englobada por laços sociais evidentes ao domínio público, a individualidade dissolve-se em uma rede de relacionamentos compulsórios ditados pela freqüência do contato no cotidiano.

Uma das principais características desses contextos é a dificuldade em veicular demandas conflitivas, o que marca fortemente a cena social por relações de solidariedade e reciprocidade "obrigatórias". A contrapartida disso, que podemos denominar de "ideologia unionista", é o desenvolvimento da "rivalidade de base faccional" (Landé 1977:xxxii), uma forma de reciprocidade hostil que age inversa mas complementarmente ao intercâmbio totalizador da vida cotidiana, provendo o campo do conflito de um componente interativo condizente com a tradição pessoalizante, na medida em que a facção fornece ao indivíduo uma rede de relações subsidiárias fundada em laços de solidariedade pessoais e dotada de uma forte referência de identidade grupal. Dividindo o quadro totalizante das relações sociais em grupos opostos e tradicionalmente rivais, o exercício da dissensão torna-se uma prática circunscrita, coletiva e, principalmente, ritualizada. Assim, podemos dizer que a "rivalidade de base faccional" é a forma clássica de organizar o campo do conflito nesses sistemas altamente integrativos, uma vez que ela consegue traduzir a linguagem da desavença para o idioma da pessoalização ao dissolver o indivíduo na facção.

Em São J oão N epomuceno, pequena cidade da Zona da M ata de Minas Gerais, essa rivalidade é tradicionalmente exercida em dois campos da vida social: no carnaval, peça de resistência da identidade local e principal instituição ritual da cidade, mediante a competição entre clubes carnavalescos e escolas de samba, e na política, pela disputa entre situação e oposição, especialmente na época de eleições, "um período de conflito autorizado com uma dimensão festiva manifesta" (Palmeira e Heredia 1997: 
161). Com o intuito de abstrairmos o ethos sanjoanense, reconstituirei a história das rivalidades carnavalesca e política da cidade para interpretar como essas instituições que cristalizam o "espírito" do seu povo reagiram ao processo de modernização próprio do "espírito" do nosso tempo.

\section{O carnaval sanjoanense}

A história do carnaval em São J oão Nepomuceno é antiga. Nas primeiras posturas da Câmara M unicipal, elaboradas em 1854, já se proibia o “jogo de entrudo" (cf. Castro 1987:165-191), o precursor do carnaval brasileiro, cuja "certidão de batismo" é uma portaria do chefe de polícia do Rio de J aneiro publicada no ano anterior, com o mesmo teor da lei sanjoanense (cf. Sebe 1986:55). Contudo, a tradição carnavalesca iria se firmar na cidade a partir do momento em que seus habitantes passaram a seguir uma tendência que transformou o carnaval em uma festa nacional, a disseminação dos clubes carnavalescos (cf. J ota Efegê 1982). Em 1907, alguns foliões da cidade fundam o Club Carnavalesco Filhos do I nferno e, a partir de então, os "festejos de M omo" tornar-se-iam uma coqueluche na pequena São J oão Nepomuceno (cf. Voz do Povo, no 15, $1 / 3 / 1908)$. Naquela época, o ponto alto do carnaval era o "préstito" realizado na terça-feira gorda, que, além dos carros alegóricos, trazia os "carros de crítica", nos quais grupos de foliões montavam pequenos esquetes jocosos, cantando versos alusivos aos "problemas" da cidade e àquilo que servia de alimento às redes cotidianas do mexerico.

O "nascimento" da rivalidade, entretanto, se configuraria a partir de uma divergência entre os diretores do clube acontecida em 1913. Em função dela, os adeptos do Filhos do I nferno dividiram-se em duas facções, o que inviabilizou o convívio entre os sócios e redundou na dissolução do clube e na fundação de duas outras associações: o Club Carnavalesco Democráticos de São J oão e o Club Carnavalesco Trombeteiros de Momo. Nos anos que se seguiram, a rivalidade nascida da dissensão evoluiu sensivelmente. Já em 1914, no primeiro carnaval com os novos clubes, as "ferinas críticas" - que desempenhariam um papel central na veiculação ritual do conflito -, em vez de se voltarem indistintamente para os fatos ou pessoas da cidade, passaram a se dirigir ao clube oponente e a seus adeptos. Isto provocava, na base da "reciprocidade hostil", um diál ogo entre os clubes, pois uma "crítica" gerava uma sucessão de réplicas e tréplicas. No ano seguinte, a rivalidade já se tornara tão virulenta que o delegado de polícia proibiria, às vésperas do carnaval, "críti- 
cas ofensivas a qualquer dos clubs" (Voz do Povo, no 326, 14/2/1915) e determinaria itinerários diferentes para os préstitos das duas associações, de maneira a evitar o embate entre trombeteiros e democráticos.

Em 1916, observa-se a constituição de uma prática que passou a marcar a dinâmica da rivalidade carnavalesca e que se tornaria um padrão persistente, sobrevivendo até os dias atuais: uma renhida disputa para saber qual clube fazia "o melhor carnaval", principalmente pela avaliação dos préstitos, mas que não culminava na proclamação de um "vencedor", na medida em que o próprio julgamento dependia apenas da opinião difusa e pessoal de um público já dividido pela paixão clubística. Isso provocava polêmicas infindáveis depois do carnaval, seja nos espaços informais, seja no próprio semanário local, reforçando a identidade dos adeptos em relação a seu clube e a rivalidade com a associação oponente. Segundo os sanjoanenses mais vel hos, essa era uma prática exercida com freqüência e entusiasmo e estendia os laços de solidariedade e rivalidade clubística para muito além do âmbito propriamente carnavalesco. Podese dizer que a identificação clubística, assim, se tornava um critério de classificação social poderoso no espaço totalizante das relações sociais.

Dois fatos ocorridos em 1917 foram muito importantes para a consolidação do clubismo e da rivalidade em São J oão Nepomuceno: primeiro, a promoção concomitante de festas pré-carnavalescas pelos dois clubes, o que estendia o "tempo do carnaval" para o mês de janeiro; e, segundo, a construção da sede social do Democráticos, inaugurada pelo agente executivo ${ }^{6}$, Dr. Péricles Vieira de M endonça, a figura política mais importante da cidade em todos os tempos (cf. Caniello 1990a:48-51). Mesmo no período da Primeira Grande Guerra, quando se observa um “esvaziamento" do carnaval, essa consolidação continuaria com a institucionalização do clube, tornado "sociedade civil". Aliás, no ano de 1918, como se fora uma contrapartida ao relativo declínio da rivalidade no carnaval, são fundados dois clubes de futebol, que se tornariam instrumentos de uma rivalidade tão radical como a dos clubes carnavalescos.

Contudo, o pós-guerra e as dificuldades econômicas decorrentes, inviabilizam a promoção dos dispendiosos préstitos, o que agrava a "crise" no Trombeteiros, enfraquecido diante de um rival institucionalmente consolidado que contava com a ajuda financeira da elite cafeeira e dos proprietários da Companhia Fiação e Tecidos Sarmento, grande tecelagem industrial instalada desde 1895 na cidade. Essa situação de "esvaziamento relativo da rivalidade", exercida por intermédio dos blocos e de "críticas avulsas" (cf. Caniello 1993:137), perdura até 1923, quando o Trombeteiros entra em nova fase, adotando o nome de N ovo Club Carnavalesco 
Trombeteiros de M omo. A partir de então, a rivalidade se exacerba ainda mais com a ampliação das atividades dos clubes e sua institucionalização: eles passam a ser definidos como "clubes sociais", suas diretorias disputam a supremacia através da construção e reforma das sedes - localizadas em lados opostos da praça principal - e da promoção de festas e eventos semelhantes em dias coincidentes durante $o$ ano preparativos da "disputa final" no carnaval.

Essa agudização da rivalidade se estende até 1926, acompanhando um período de aquecimento das disputas entre situação e oposição no município, as quais, então, codificavam uma espécie de "divisão" da cidade em duas metades beligerantes. Em função dessa divisão, ocorre o único episódio sangrento da história política local (ver abaixo), que iria marcar profundamente a estrutura do faccionalismo, além de determinar uma fase de refluxo da rivalidade no carnaval que duraria até 1933. Nesse interregno, os clubes praticamente abandonam o carnaval de rua e voltam-se para a promoção do "carnaval interno" que supunha - como as festas sociais -, mas não explicitava, o embate ritual.

Em 1934, o carnaval retoma seus dias de maior animação, pois os dois clubes voltam a realizar os préstitos. Além disso, a rivalidade passa a se constituir em uma espécie de código hegemônico no carnaval ao estender-se, além dos tradicionais clubes que congregam a elite e as classes médias, para novas agremiações que se formam - como entre o Rancho dos Fenianos, composto pela população negra, e o Rancho Colar de Pérolas, composto pela população mestiça, ou entre o Bloco dos Alinhados e o Bloco dos Turunas, de extração popular. Observa-se, a partir desse período, um novo movimento de exacerbação da rivalidade clubística que passa, contudo, por um desalinhamento em relação às oposições políticas: cada vez mais, a rivalidade clubística restringe-se ao âmbito das próprias associações.

Um dos elementos rituais mais importantes da tradição carnavalesca surge naquele momento: em 1935 realiza-se, pela primeira vez, a "bataIha de confetes" que, desde então, passa a abrir os festejos carnavalescos, servindo como marco inicial dos embates momescos entre os clubes. Realizada na principal rua da cidade e promovida pelos comerciantes que nela tinham seus estabelecimentos, a chamada "Sesquipedal" aglutinava a população às vésperas do carnaval - na quinta ou sexta-feira - para que, munidos de confete, serpentina e ampolas de lança-perfume, se integrassem na vaga de animação que se iniciava. A certa altura, saía, concomitantemente, de cada clube um grupo de foliões conduzindo o estandarte da agremiação, que desfilava pela cidade com destino à Rua do Sarmen- 
to. Lá chegando, uma verdadeira guerra era protagonizada pelos adeptos dos clubes, que se rivalizavam na tentativa de "tomar" o estandarte conduzido pelo adversário e rasgá-lo, em meio à algazarra de seus pares.

A Segunda Guerra M undial impõe um certo retraimento ao carnaval sanjoanense, fazendo com que os clubes voltem a privilegiar o "carnaval interno", com a promoção de bailes e festas interditados aos sócios do clube contrário. Entretanto, imediatamente depois do fim da guerra, se verifica o "período de apogeu" do clubismo na cidade, o qual é marcado pela agudização da rivalidade e por uma tendência cada vez mais pronunciada de "controle" dela, vale dizer, de desinstrumentalização da oposição clubística. Em 1946, por exemplo, as diretorias dos clubes firmam um acordo em relação aos bailes pré-carnaval escos semanais, segundo o qual, em lugar da tradicional concomitância, cada clube deveria promover suas prévias em dias alternados: eram as famosas "sabatinas" e "domingueiras", que evitavam embates diretos pela "melhor animação". Além disso, o período também é profícuo no que se refere à vida associativa como um todo, pois os clubes de futebol - Mangueira e Botafogo - são reorganizados e passam a disputar jogos nos fins de semana, que produzem, tal como os clubes carnavalescos, uma rivalidade pronunciada entre seus torcedores.

No fim da década de 40, surgem as escolas de samba e o carnaval dos clubes se sofistica: além dos préstitos tradicionais e das prévias, são promovidos bailes infantis, concursos de fantasia, el eições de rainha do carnaval etc. O coroamento dessa fase se dá com a reedição da "batalha de confetes", a partir de 1953, e com o surgimento de outro componente ritual, que fechava o carnaval, agindo como um evento homólogo, mas invertido, da "batalha", as "visitas": no último dia do carnaval, uma "embaixada" de um dos clubes, composta por alguns diretores e foliões, ia até a sede do clube rival portando seu estandarte; lá chegando, era efusivamente recebida pelos adversários e os hinos dos dois clubes eram entoados. Logo em seguida, o clube visitado retribuía a homenagem, visitando o oponente, em um congraçamento que fechava o "tempo do carnaval" e que preparava o espírito dos torcedores para as infindáveis discussões sobre o vencedor do carnaval.

O advento da década de 60 trouxe consigo o declínio da rivalidade clubística. Ao mesmo tempo que os clubes passam a se dedicar exclusivamente ao "carnaval interno" - seguindo, aliás, uma tendência nacional -, no carnaval de rua, as "críticas", organizadas por grupos formados ad hoc, descambam para ataques pessoais. $\mathrm{O}$ que parece ter ocorrido nesse momento é uma substituição da rivalidade clubística como elemen- 
to ritual, grupal e conjuntivo por um sectarismo disjuntivo e mais individualizado. O término das "visitas", noticiado pelo jornal local em 1966, e o início de uma crise financeira que praticamente levaria ao fechamento do Democráticos anos depois, determinariam o fim da rivalidade clubística carnavalesca no último lustro dos anos 60.

Sem embargo, como a ocupar o vazio deixado pelo declínio dos clubes, é precisamente nessa época que as escolas de samba passam a protagonizar o carnaval de rua. No início dos anos 70, já se processa um crescimento das escolas com a adesão crescente da população, iniciada, como apontam vários informantes, pela atração dos adeptos dos clubes pelo carnaval das escolas. Com a consolidação da Escola de Samba Esplendor do M orro e da Escola de Samba A venida Carlos Alves (ESACA), que aos poucos vão construindo suas sedes e diversificando suas atividades sociais e, assim, tornando-se agremiações aglutinadoras de adeptos apaixonados, gesta-se uma nova ordem de identificação grupal bastante correlata àquela dos tradicionais clubes carnavalescos. Assim, a estrutura faccional de duas associações se embatendo pela supremacia no carnaval é reeditada com a consolidação das escolas de samba, ainda que elas jamais tenham tido tanta abrangência em outros campos da vida social como os clubes. É exatamente isso que ocorre na década de 80 , quando os desfiles das escolas de samba passam, definitivamente, a polarizar a atenção da população, que passa a acorrer aos clubes apenas para os bailes.

A nalisando o carnaval atual, verifica-se grande semelhança com os antigos "festejos de momo" (cf. Caniello 1993:176-180). Em primeiro lugar, o seu caráter totalizador: além de aglutinar praticamente toda a população da cidade, inclusive os "sanjoanenses ausentes" que invariavelmente passam as férias na cidade, o assunto reinante em todas as rodas é o carnaval. Além disso, o que é mais importante é a existência de duas agremiações que se rivalizam na disputa pela hegemonia da animação carnavalesca, polarizando "faccionalmente" a população. Pudemos avaliar o comprometimento que as pessoas têm com essa rivalidade, acompanhando todas as fases do carnaval de 1990.

Tudo se inicia meses antes dos festejos, quando os partidários de ambas as agremiações - pessoas de todas as classes sociais - se dedicam à preparação das fantasias, alegorias e adereços que irão compor o desfile de domingo. As costureiras, divididas de acordo com sua ligação com as escolas, empregam praticamente todo o seu tempo na confecção das fantasias; as diretorias das escolas mobilizam-se na preparação dos carros alegóricos e na organização das alas; as baterias ensaiam promovendo animadas prévias carnavalescas em suas quadras nos finais de semana. 
O que mais evidencia o vigor da rivalidade é o fato de toda essa preparação ser envolta no mais estrito segredo: tudo é preparado com grande discrição e o que mais se teme é o "furo" - a descoberta, por parte dos rivais, dos modelos das fantasias da escola a serem usados no grande evento.

Outra homologia entre o carnaval atual e os de antanho é que o clímax continua sendo o desfile, que mantém o caráter ritual dos antigos préstitos e que há muito tempo é realizado no domingo. Quanto à sua forma, ele pode ser comparado, guardando-se as proporções, ao desfile das escolas de samba do Rio de J aneiro, mas ele não é competitivo como o festival de referência: tal como manda a tradição, não há comissão julgadora, o vencedor não é proclamado e a "vitória" continua a depender da difusa "opinião pública", dividida pela paixão a uma ou outra escola. Como antigamente, terminado o carnaval, as discussões se prolongam e o sectarismo dá o tom das conversas e, assim, a "pugna carnavalesca" objetivada pela rivalidade é, como foi desde sempre, demonstrativa: a cidade mudou, mas continua sendo um espaço totalizador movido pelo valor da "união"; o carnaval mudou, mas continua sendo uma arena metafórica em que a dissensão se traveste de rivalidade, permitindo que as pessoas, mais ritualmente do que nunca, exerçam o conflito em um idioma pessoalizado, participando de uma facção que hoje é a escola de samba.

\section{As modulações do faccionalismo}

Temos falado em faccionalismo para definirmos um tipo de sistematização de padrões de conduta no âmbito da organização social operado mediante a rivalidade entre grupos com identidades próprias definidos diádica e opostamente no interior da totalidade social englobadora e "unionista" da pequena cidade. A rivalidade assim produzida informa uma "reciprocidade hostil" que permite a veiculação ritual e coletiva do conflito, circunscrevendo-o a arenas metafóricas como a do carnaval. Contudo, um elemento básico do faccionalismo é o seu caráter dominantemente político, pois normal mente ele é uma estrutura codificada por oposições entre grupos organizados que disputam o poder.

Esta é, precisamente, a matriz histórica do faccionalismo em São J oão Nepomuceno, pois, já no período da fundação do município, na primeira metade do século XIX, o campo das relações políticas era organizado sob "a dicotomia 'situação' e 'oposição', norma fundamental e expressão política da sociedade brasileira desde o período colonial” (Quei- 
roz 1977:170): no caso, pela disputa entre liberais e conservadores. Essa norma se tornou um padrão no campo das relações políticas em São J oão Nepomuceno, permanecendo operante até os dias de hoje, e caracterizando também o período eleitoral como uma arena em que o conflito é exercido ritualmente através de uma hostilidade autorizada entre facções (cf. Caniello 1993:181-277). A ssim, tal como o clubismo, o partidarismo informa estruturalmente a mesma coisa: um embate circunscrito, mas vigoroso, entre grupos oriundos do contexto social totalizador da pequena cidade, organizados com base em uma identidade opositiva em momentos rituais que refratam o tempo cotidiano.

É exatamente a história da relação entre esses dois campos da vida social sanjoanense que pode nos indicar de que forma o padrão pessoalizante reage diante do "processo de individualização" promovido pela expansão do capitalismo, cuja pressão também é sentida nas pequenas cidades, crescentemente integradas na sociedade inclusiva. $O$ que nos autoriza a supor que havia uma espécie de tensão entre o tradicional e o moderno na ideologia local é a formulação de um discurso dúbio sobre a rivalidade, através da construção de uma representação do fluxo histórico no qual "presente" e "passado recente" se contrastam como realidades em que a rivalidade pouco influi na vida social como um todo com um "passado remoto" quando ela verdadeiramente codificava o panorama social da pequena cidade.

O passado é visto como "a época da política braba", quando a divisão política redundava em um faccionalismo que alinhava clubes, associações, bandas de música, jornais e até farmacêuticos e médicos em duas metades opostas e beligerantes que classificavam indivíduos e instituições, incluindo-os em uma ordem de oposição totalizadora que condicionava seu trânsito nas relações sociais mais gerais. Como demonstra a historiografia política da República Velha, essa era a configuração societária dominante nas pequenas cidades brasileiras de então (cf. Leal 1986 e Queiroz 1977). É o que denominamos faccionalismo clássico: a vida social é organizada a partir de uma clivagem da totalidade globalizadora da pequena cidade - a qual é codificada pelos grupos políticos que disputam o poder, normalmente sob a fórmula situação vs. oposição - , o que produz arenas de solidariedade e identidade (a própria facção) e arenas de hostilidade e rivalidade (as relações com a facção oposta). Um fator importante nessa configuração é que as facções políticas não são definidas a partir de posições programáticas diferenciais, mas por alinhamentos pessoais expressos modelarmente em relações de patronagem e no clientelismo (cf. Caniello 1990a). 
N a São J oão N epomuceno da primeira metade do século $X X$, isso ocorre com a disputa pelo domínio da "máquina" (Scott 1969) do Partido Republicano Mineiro (PRM), em um momento em que a descentralização federativa articulada a uma estrutura eleitoral viciada garante aos partidos republicanos estaduais uma hegemonia incontestável, conferindo aos "chefes políticos" locais grande poder de influência como mediadores entre a população da pequena cidade e o governo estadual. Assim, durante a República Velha, o jogo político é marcado por uma forte animosidade entre situação e oposição, cujo clímax se verifica durante o período eleitoral, mas que define os padrões de sociabilidade mais gerais ao "dividir" a cidade no seu próprio cotidiano. Contudo, ao contrário do que afirma Queiroz (1977:170), em São J oão Nepomuceno, o "ajuste violento" não era a "forma normal" de veiculação da dissensão. Longe disso, o que ocorria na cidade era um sistemático controle da violência pela ritualização das disputas, através de um enfrentamento aberto e violento apenas no plano da oratória, tanto nos espaços de relação interpessoal do cotidiano quanto nos comícios e no proselitismo dos jornalistas.

Essa dinâmica da disputa política vai se agudizando na medida em que a oposição se organiza mais organicamente no município, a partir da segunda metade dos anos 20 . O processo político torna-se cada vez mais conflituoso, e o aparelhamento das pessoas e instituições envolvidas mais radical, como pudemos verificar em relação à própria rivalidade clubística. O ano de 1926 pode ser considerado uma espécie de clímax dessa situação, tendo em vista uma conjunção de acontecimentos que exacerbariam ainda mais a tendência de radicalização da rivalidade faccional. $O$ primeiro desses fatos é o falecimento do coronel J osé Braz de Mendonça, fundador da oligarquia detentora da sigla do PRM municipal e dona de uma hegemonia situacionista antiga e persistente, e a ascensão de seu fiIho Dr. Péricles de M endonça à posição de "chefe" do PRM local. Entretanto, a sucessão não foi consensual e a disputa pela liderança do partido majoritário ocasionou o segundo fato: o aparecimento dos dissidentes 7 que "racham" com os periclistas, partidários da oligarquia dominante. Esse estado de coisas se encaminharia para a configuração de um terceiro fato fundamental: a consolidação do Partido Dissidente, fundado pelo coronel J osé Henriques Pereira Brandão, político de família tradicional da cidade, contemporâneo e antigo aliado do coronel J osé Braz, que passou a atrair membros da elite local descontentes com a sucessão. A fundação do jornal A Cruzada foi outro fator decisivo, pois a folha passou a polemizar virulentamente com a Voz do Povo, jornal situacionista, reforçando a rivalidade faccional. 
A tendência de exacerbação atingiu o seu ápice no dia 7 de setembro de 1926, quando ocorreu o único episódio sangrento na história política da cidade. Uma polêmica banal, a troca do nome da praça principal proposta pelos dissidentes e obstruída na Câmara M unicipal pela maioria periclista, levou as duas facções - cujos líderes se haviam ausentado para a posse do presidente do Estado - a transformarem a referida praça em um verdadeiro "campo de batalha". Os dissidentes, inconformados com a manobra periclista, saíram em comissão até a praça e, acompanhados de sua banda de música e sob o espocar de foguetes, tentaram afixar a placa com o novo nome. Os periclistas reagiram prontamente e, em meio à discussão, houve uma troca de tiros que deixou quatro pessoas mortas, inclusive o diretor da Voz do Povo.

Este episódio marcaria profundamente o quadro das relações políticas em São J oão N epomuceno e redefiniria, como veremos, a própria estrutura do faccionalismo na cidade. A avaliação dos "acontecimentos de 1926" operou como uma espécie de advertência em relação ao potencial de violência do divisionismo político exacerbado, contraditório ao ideário "unionista" do padrão pessoalizante tipicamente brasileiro, equilibrado pela ritualização dos conflitos na pequena cidade. A matéria publicada pela Voz do Povo, ao completarem dois meses do evento, é modelar:

“Azas pandas, enfunadas pela nortada rija do infortunio, a alegria completa emigrou de nosso meio: no ar, volteando, como farrapos negros, os corvos voejam, farejando a reputação alheia e nella fincando suas garras aduncas, emquanto a Discordia - essa megera terrível - faz o seu trabalho deliquescente invadindo os lares, separando os paes dos filhos, partindo affectos, desligando amigos de infância e de muitos annos, fazendo esquecida a gratidão, reflectindo-se nas relações de familia, para a construção de uma Babel nova e ainda mais perniciosa que a da lenda cristã. [...] O sangue humano não alicerça partidos. O seu derramamento injustificado quebrou a harmonia e a paz reinantes na honrada familia sanjoanense, produzindo o desaggregamento de energias poderosas até então vinculadas aos sãos preceitos do Perdão, do Amor e da Caridade" (Voz do Povo, no 927, 7/11/1926).

O que ocorre depois, além do já apontado refluxo da rivalidade clubística, é uma reacomodação das relações políticas, com o crescimento dos dissidentes na eleição municipal de 1927, principalmente entre o eleitorado urbano. Contudo, a perspicácia política do Dr. Péricles fez com que sua facção se alinhasse à Aliança Liberal, permitindo a manutenção 
de seu poder de mando mesmo com a Revolução de 30, em virtude da qual foi nomeado interventor municipal.

No entanto, os anos 30 testemunharam um momento de transformações importantes no panorama social do país, que se relacionavam perfeitamente com as tendências modernizadoras defendidas pela Revolução: a inserção mais efetiva da sociedade brasileira no âmbito do capitalismo internacional (cf. Abreu 1984:13) e, conseqüentemente, a definição de um padrão de relações sociais, políticas e econômicas cada vez mais pautado pela lógica do mercado, seja em sua dimensão propriamente econômica, com o impulso do processo de industrialização (cf. A breu 1984:30), seja na base ideológica que o informa, com a reivindicação de um model o político fundado no liberalismo e em instituições democráticas (cf. Fausto 1990:236, passim). Nos nossos termos, a emergência de um padrão ético individualista como modelo dominante 9 .

Isso teria provocado o que Edgar Carone (1978:6) chama de “caráter de transitoriedade" e Boris Fausto (1990:237) de "período de acomodação". Na sua primeira fase - entre 1930 e 1937 - , a República N ova articulava tendências modernizadoras com formas tradicionais de poder político - nas pequenas cidades, principalmente, as vel has oligarquias mantinham-se operantes, já que conseguiam capitalizar para si elementos do ideário liberal, principalmente processos eleitorais livres e legais, submetendo-os à preservação de estratégias tradicionais de cooptação de eleitores (cf. Camargo 1983:127). Pode-se dizer que, naquele momento, a sociedade brasileira reagia ambiguamente, formulando um modelo ético dúplice que articulava o tradicional ao moderno.

Em São J oão Nepomuceno, um indício importante aponta para o mesmo processo dúplice: a redefinição da estrutura faccional. Por um lado, como já vimos, opera-se a restauração da rivalidade clubística e, por outro, o padrão de disputas eleitorais entre situação e oposição continua operante, mas percebe-se uma certa acomodação com a articulação de um novo quadro de composições políticas entre as antigas facções pela necessidade de aliar o poder de voto da velha oligarquia ao discurso modernizador crescentemente hegemônico. Como resultado, inicia-se um processo de "flexibilização" do faccionalismo realizado, fundamentalmente, pela desinstrumentalização da rivalidade política, que passa a perder seu poder codificador na construção dos alinhamentos faccionais (cf. Caniello 1993:224-227).

O golpe de 1937 e o regime de exceção impõem a "suspensão" das atividades políticas na cidade, e a Segunda Guerra M undial o arrefecimento da rivalidade clubística. Contudo, a partir da restauração demo- 
crática e do fim da guerra, a tendência de flexibilização do faccionalismo retoma seu curso.

Em primeiro lugar, reeditam-se as disputas eleitorais entre facções políticas organizadas com base nos grupos tradicionais - periclistas e dissidentes - , mas a nova ordem el eitoral determina um inusitado equilíbrio entre a antiga oligarquia alijada do poder no Estado Novo e o grupo situacionista emergente, configurando-se uma recomposição no quadro político com a aliança das antigas facções rivais, que passam a gozar de uma tranqüila hegemonia política consensual. Assim, é num fluxo de permanência na mudança que a política municipal transcorre até o final da década de 50 . Se há, claramente, uma evolução em termos dos princípios institucionais na escol ha eleitoral e na organização partidária, um desaparelhamento faccional e um comportamento político mais equilibrado, há, por outro lado, a manutenção dos mesmos grupos dirigentes "oligárquicos", uma estrutura de poder calcada em uma hegemonia indiscutível da situação e a sobrevivência de um estilo político calcado na "lógica da patronagem" (cf. Caniello 1990a:50-51; 1993: 239-247).

Em segundo lugar, vimos que esse foi o período do "apogeu" da rivalidade clubística na cidade, tanto pela consolidação dos clubes carnavalescos, e por seu investimento no carnaval, quanto pelo aparecimento dos clubes de futebol, que criaram um novo "campo" para o exercício da rivalidade. Contudo, conformava-se um novo tipo de faccionalismo que se definia por dois aspectos principais: a rivalidade era exercida em três arenas diferentes - na política, no carnaval e no futebol -, e a estrutura política perdia definitivamente o poder de valer-se das instituições clubísticas - ou de outras quaisquer - para uma instrumental ização direta das dissensões partidárias. Configurava-se, a partir de então, o que conceituo como faccionalismo em série (cf. Caniello 1990a:52-53; 1993:299, passim): uma ordem social que pulveriza a rivalidade característica dos sistemas totalizadores da pessoa por diversos campos da vida social sem, entretanto, estabelecer alinhamentos inclusivos que indiquem a formação de dois grandes blocos antagônicos e excludentes, classificatoriamente falando ${ }^{10}$. No caso de São J oão Nepomuceno, esse modelo faccional se caracteriza pela ausência de identificação direta entre o pertencimento do indivíduo às facções políticas e sua adesão às associações esportivas e carnavalescas.

Esse tipo de arranjo é essencialmente dúplice, na medida em que mantém a rivalidade como uma prática importante para a veiculação do conflito por intermédio de oposições grupais virulentas, mas a circuns- 
creve a ambientes e momentos rituais específicos, impossibilitando o aparelhamento dualista do grupo social. O que ocorre é, ao mesmo tempo, uma agudização da rivalidade e uma acomodação de "elementos novos". Se, por um lado, as associações são definidas contrastivamente em função de uma rivalidade opositiva de matriz tradicional, a adesão a elas torna-se cada vez mais "livre", passando a depender mais da escolha do indivíduo e menos de imposições classificatórias inclusivas. Isso "apaziguou" as relações, mas manteve o código da rivalidade:

“Tinha o Trombeteiros e o Democráticos, clubes de carnaval; então, entre esses dois clubes era uma disputa ferrenha. Mas, em compensação, tinha os clubes de futebol [...] que era também uma disputa ferrenha e braba, quente mesmo, mais pra briga do que pra outra coisa. Depois, tinha a disputa política. [...] O pessoal trocava, entendeu? É por isso que eu tenho a impressão que o problema do desforro pessoal acabou. [...] A coisa amainou um pouco, a coisa não ficou tão ferrenha porque o sujeito não tava podendo ofender o outro; porque lá na reunião, lá na política, o cara fazia parte [do grupo] dele. Eu não podia brigar porque na outra associação eu ia ter que conviver com ele. Quer dizer, o pessoal era o mesmo que participava de todas as três [...], como é que eu vou fazer para ofender um cara que é do outro partido lá, como é que eu vou fazer para ofender esse cara que é do PSD se ele é meu amigo lá no Trombeteiros?" (J osé M aria, 60 anos, empresário, ex-candidato a prefeito em duas eleições na década de 70)

O advento da década de 60, no entanto, traz importantes modificações no panorama social das "cidades pequenas" com a consolidação da "modernização" da sociedade brasileira, pois a "política de nacionalismo desenvolvimentista" (Skidmore 1982:205) de J uscelino Kubitschek, definitivamente, inseriria o país no âmbito do capitalismo mundial (cf. Singer 1984:225). Além disso, uma incontestável evolução da sociedade brasileira em termos demográficos, sociais e econômicos acabaria por criar condições bastante propícias ao desenvolvimento de um mercado interno amplo e vigoroso (cf. Sodré 1963:361-362). Essa conjunção de fatores, articulada à expansão da malha rodoviária, a um processo de urbanização crescente e a um grande incremento dos meios de comunicação de massa, consolidaria a disseminação definitiva da lógica de mercado em todo o território nacional, e esse movimento viria a impactar o modo de vida tradicional das "cidades pequenas".

Em São J oão Nepomuceno, esse processo se desencadearia, principalmente, pelo estabelecimento de relações mais eficientes entre a pe- 
quena cidade e a sociedade inclusiva, relações estas fomentadas por uma significativa melhora de suas estradas e das telecomunicações, particularmente com a inauguração de uma repetidora de sinais de televisão em 1962. Essas novas condições estimulariam a formulação de um discurso modernizador dominante na época, o qual veicularia uma categoria central da cosmologia histórica do faccionalismo: "o fim da rivalidade". De fato, a diversificação da vida social na cidade e o crescente desequilíbrio entre o Democráticos e o Trombeteiros, aquele em franca decadência e este em plena ascensão, viriam a mitigar a tradicional rivalidade entre os clubes. No início dos anos 80, a fundação do "country clube" do Trombeteiros, a moderna sede campestre do "clube social" que já fora "clube carnavalesco", parece ter completado esse processo, pois sua excelente estrutura passou a atrair não só as "famílias trombeteiras", mas também as "famílias democráticas", que já não podiam contar com o "clube do coração" para seus momentos de lazer. Embora aqueles chamados e autodenominados "renitentes" de ambos os clubes ainda resistissem, as novas gerações consideravam a rivalidade clubística apenas como um traço de uma velha tradição decaída nos novos tempos.

Porém, se somos instados a estabelecer uma relação de causalidade entre as mudanças na economia nacional, a hegemonização da lógica de mercado com sua pressão modificadora e a transformação de padrões de sociabilidade tradicionais colocados pelo "discurso nativo", dois fatores importantes contraditam essa correspondência: o quadro das relações políticas e a própria estrutura da rivalidade carnavalesca.

Em primeiro lugar, consideremos o campo das disputas políticas e sua dinâmica no início dos anos 60 . Na década anterior, as antigas facções aliaram-se em virtude de um inusitado equilíbrio de forças entre os periclistas, reunidos no então inexpressivo Partido Republicano, e os dissidentes, detentores da administração local durante o Estado Novo, então filiados ao Partido Social Democrata (PSD), partido majoritário no estado. Entretanto, em 1960, Magalhães Pinto, da União Democrática Nacional (UDN), elege-se governador de M inas Gerais, o que faz com que o Dr. Péricles e seu PR encontrem uma linha de coligação eficiente que Ihes dá uma base segura de sustentação eleitoral, garantida pelo alinhamento com a administração estadual e sua "máquina política". Assim, o veIho chefe rompe a aliança conjuntural com seus adversários históricos, a disputa política retoma a tradicional polarização e o grupo do Dr. Péricles reassume o mando do poder local nas eleições municipais de 1962, posição que se estabiliza a partir do golpe de 1o de abril de 1964, já que Magalhães Pinto fora um dos seus principais articuladores. 
Essa configuração se consolidou ainda mais a partir da nova legislação el eitoral imposta pelos militares após a derrota das forças situacionistas em M inas e na Guanabara nas eleições de 1965. Com a dissolução dos antigos partidos e a imposição do bipartidarismo, a relação situação vs. oposição passa a ser a única alternativa possível no jogo eleitoral. Sem embargo, o estado de exceção e seu recrudescimento praticamente impedem o exercício do oposicionismo, considerado "subversivo" na visão de um regime que se torna crescentemente discricionário. Por outro lado, a morte do Dr. Péricles, em 1966, "esvazia" a tradicional rivalidade política ao destituí-la de sua peça mais importante. Por isso, em mais um lance de pragmatismo político, as antigas facções voltam a se aliar, agrupando-se agora sob a sigla do partido oficial, a Aliança Renovadora Nacional (ARENA). Durante a década de 70, exercem uma hegemonia incontestável no município, vencendo eleições definidas pela influência das forças majoritárias estaduais indicadas pela cúpula federal do regime militar. Entretanto, uma regra das eleições municipais nesse período era o lançamento à "cabeça de chapa" dos vice-prefeitos em fim de mandato, o que demonstra que o campo político ainda guardava a marca das antigas facções, conjunturalmente unidas sob a mesma sigla partidária mas organicamente separadas pela alternância no exercício do mando político:

\footnotetext{
“Bolote [prefeito (1970-1973)] tinha o compromisso com o Zé Salu, na outra eleição trabalharia para ele ser prefeito; então na outra eleição o Zé Salu foi prefeito [1973-1976] e o Antonio Cavalheiro, vice. Aí, chegou as eleições, então o Cavalheiro entrou pra prefeito [1977-1982] e o Vagner, vice. Daí a seis anos, o Vagner elegeu-se prefeito [1982-1988]" (Célio, 46 anos, empresário, prefeito da cidade).
}

Com a "distensão" e a volta da normalidade democrática, o jogo político na cidade vai voltando à sua habitual polarização, uma vez que os novos grandes partidos, o Partido Democrático Social (PDS) e, depois, o Partido da Frente Liberal (PFL), por um lado, e o Partido do M ovimento Democrático Brasileiro (PM DB), por outro, passam a acomodar as forças políticas locais e as eleições readquirem o caráter de disputa tradicional. Nas eleições de 1988, dá-se a "grande virada" no município: seguindo a tendência de crescimento estadual do PMDB, que elege o governador, enfim um candidato oposicionista vence em São J oão Nepomuceno. Apesar da derrota do situacionismo, a vitória peemedebista na cidade parece justamente confirmar uma regra de comportamento político que tem nos "mediadores" seu elemento principal: 
“Célio Filgueiras Ferraz será o primeiro prefeito el eito do PMDB no município, após 20 anos de governo dos antigos partidos, ARENA, PDS e do atual PFL. Para a cidade será uma mudança radical necessária, pois doravante a administração municipal estará afinada com o atual governador N ewton Cardoso e o deputado Elmo Braz Soares que, antes, pouco podiam fazer por nossa comunidade. Cremos ter sido este o grande motivo que levou os eleitores a apoiar o candidato do PMDB" (Voz de São J oão, no 2.667, 18/11/1989).

Portanto, mesmo diante das radicais mudanças políticas e econômicas verificadas entre 1960 e 1990 na sociedade brasileira, o jogo político em São J oão Nepomuceno manteve a sua estrutura tradicional fundamentada no padrão pessoalizante: a rivalidade entre facções políticas antagônicas, a hegemonia do situacionismo vinculado ao poder estadual e o comportamento político baseado na lógica da patronagem, apesar de suas acomodações conjunturais. Entretanto, o que se verifica é que o vigor da rivalidade faccional no campo político aprofunda sua característica ritual, pois ela vai gradativamente perdendo o poder totalizador e circunscrevendo-se ao "tempo da política":

“A política em São J oão é sempre uma política muito calma e só se fala em política em ano de el eição [...]. Todos vivem harmonicamente, na época de eleição é que a gente separa. [...] Quando chega a política, então há o afastamento; acabou a política, se une tudo." (Heleno, 68 anos, advogado, viceprefeito)

No caso da rivalidade carnavalesca, como vimos, evidencia-se um processo homólogo. Com o declínio dos clubes e a ascensão das escolas de samba, reedita-se uma realidade estruturalmente idêntica à dos antigos "festejos de momo" e seu principal elemento, a disputa. Contudo, tal como na política, o exercício ritual da rivalidade é agudizado, ao restringir-se, cada vez mais, ao "tempo do carnaval":

“[A rivalidade] é diferente, porque a escola de samba acontece uma vez por ano. As pessoas em São J oão não vivem em função das escolas de samba o ano todo, é quando tá chegando o carnaval. No clube, as críticas, as coisas, apesar de só serem feitas no carnaval, a rivalidade existia o ano inteiro. [...] Escola de samba tem só no carnaval, mas é muito acirrado" (Plínio, 32 anos, industriário, presidente do Trombeteiros). 
Portanto, no início dos anos 90, configura-se a última fase do processo de desinstrumentalização da rivalidade tradicional, que conceituei como faccionalismo pontual (cf. Caniello 1993:319, passim): a rivalidade perde definitivamente aquele poder classificatório que condiciona o trânsito do indivíduo nas diversas áreas da vida social, tornando-se ainda mais circunscrita a momentos especiais e demarcados que veiculam enfrentamentos grupais conflituosos. Por outro lado, ela permanece sendo uma categoria definidora da "reciprocidade hostil", que contrabalança ritualmente $o$ "unionismo" globalizador da vida cotidiana e sua lógica mais profunda, a ética pessoalizante. Assim, no faccionalismo pontual preserva-se a estrutura definidora da rivalidade, exacerbando seu caráter ritual, mas o indivíduo é libertado da classificação totalizadora proveniente do pertencimento à facção, cobrindo-se de uma ideologia que pontua a escolha individual como elemento crítico de suas opções partidárias ou carnavalescas.

\section{Ethos: tradição, mudança e síntese}

Uma impressão geral impõe-se a partir da reconstituição e análise da história do faccionalismo em São J oão Nepomuceno: ao lado das mudanças na sua forma de expressão, principalmente no que se refere ao caráter totalizador das oposições faccionais, evidencia-se uma permanência estrutural significativa de sua lógica interna - a ritualização faccional do conflito. Levando-se em conta que essa ritualização é uma face significativa do conjunto de valores relevantes que define o padrão de sociabilidade na pequena cidade, podemos dizer que o "valor maior", aquilo que cristaliza seu "jeito de ser", mantém sua centralidade: uma ideologia "unionista", marcada pela ojeriza ao conflito interindividual - um dos elementos estruturadores do que chamamos de padrão pessoalizante de relações sociais.

Isso ocorre porque o sistema social - ou os indivíduos que, através de relações com outros indivíduos, constroem a sua cultura - tem uma capacidade adaptativa obj etivada por processos de modulação ética (cf. Caniello 1990a; 1993:300)11: em face de pressões modificadoras provindas de macroprocessos que fomentam a hegemonia de determinadas estruturas - vis-à-vis a expansão capitalista e sua exigência ética individualista - , o "estilo" próprio de um povo se ajusta a novos influxos, mantendo, contudo, sua coerência estrutural. Assim, a modulação é uma operação legitimadora, na medida em que articula os mores da identidade tradicional às exigências que a modernidade impõe, através de uma ope- 
ração que aprofunda a lógica tradicional ao nível do inconsciente, na mesma medida em que modifica seus conteúdos práticos pela reelaboração dos modelos conscientes que veicula.

É essa lição que podemos derivar da reconstituição do ethos sanjoanense a partir do ciclo de modulações faccionalismo clássico $\rightarrow$ faccionalismo em série $\rightarrow$ faccionalismo pontual: em face de uma relação cada vez mais orgânica com padrões éticos individualistas que passam a exercer maior influência na vida social, a rivalidade torna-se crescentemente encapsulada naquilo que sempre definiu sua internalidade: um caráter ritual que coalesce a ordem totalizadora do grupo à individualidade dos sujeitos que o compõem. Como vimos, essa flexibilização do faccionalismo é claramente relacionada com sua desinstrumentalização, ou seja, com uma crescente abertura à "escolha" dos indivíduos em relação à sua inclusão em uma facção que o identifica como pessoa. Sem embargo, a rivalidade faccional como código estruturante da veiculação do conflito permanece, tanto na política quanto no carnaval, como um elemento crítico do "jeito de ser" dos sanjoanenses.

O que talvez torne essa constatação relevante é que o processo particular que descrevi se desenvolveu em um momento histórico fundamental para a sociedade brasileira e que, como demonstrei, conformou a própria ocorrência desse processo: nossa inclusão na modernidade. Seja pelos progressos econômicos do país que levaram à sua inserção mais efetiva no sistema mundial, seja pelas transformações políticas que aperfeiçoaram a democracia na nossa república tardia, seja pelas novas ideologias liberais que se disseminaram em função disso, seja mesmo pelo resgate da "brasilidade" no futebol, na arte, na música, na literatura e na tradição popular, o século XX testemunhou a consolidação de nossa identidade nacional. Isto ocorreu tendo como pano de fundo uma tensão, aliás característica do processo de formação nacional brasileiro desde a sua origem (cf. Caniello 2001): o embate entre nossa tradição pessoalizante e a ética individualista da chamada "ordem social competitiva" (cf. Fernandes 1987:149, passim). Ora, a solução brasileira para as tensões produzidas por esse encontro foi exatamente uma operação condizente com o nosso "estilo", historicamente formado por "um processo de equilíbrio de antagonismos" (Freyre 1994 [1933]:53) fundado no "horror às distâncias que parece constituir [...] o traço mais específico do espírito brasileiro" (Holanda 1988 [1936]:110): a "institucionalização do intermediário" (DaM atta 1993:147).

Embora eu não esteja estabelecendo nenhuma relação de causalidade entre os dois fluxos de eventos, pretendo apontar uma homologia 
significativa entre um "microprocesso" e um "macroprocesso", ocorridos concomitantemente e construídos similarmente. O que chamei de "opção dúplice" (Caniello 1993:324) parece ter sido a operação central da modulação objetivada tanto no âmbito da pequena cidade quanto no da própria sociedade brasileira como um todo nas situações históricas em que a tradição e a modernidade se tensionaram, pois o que ocorreu, tanto em um caso como no outro, foi uma articulação engenhosa entre val ores tradicionais e modernos, sem contudo abalar a posição central da ênfase pessoalizante do nosso "jeito de ser".

A principal conclusão a que se chega é que o ethos entendido como um fato sociológico e histórico sintético explicita, sobretudo, a preeminência do "espírito de um povo" (Volsksgeist) - ou seja, o âmago da tradição que o constitui - sobre o "espírito do tempo" (Zeitgeist) - ou seja, a conjuntura que o pressiona. Quer dizer, mesmo diante de pressões modificadoras extensas e intensas provocadas pela hegemonização de tendências contraditórias à ordem ética tradicional, aquele padrão que define o "estilo" ou o "caráter" do grupo social ao informar códigos de conduta, parâmetros morais, critérios de identidade e sentimentos de inclusão mantém sua integridade, modulando-se ao sabor do "espírito do tempo". Portanto, esta análise do ethos sanjoanense, bem como minhas ilações sobre o ethos nacional brasileiro (cf. Caniello 2001) procuram evocar tão-somente aquele "mesmo tipo de mudança cultural, induzida por forças externas, mas orquestrado de modo nativo, que vem ocorrendo há milênios" (Sahlins 1990:9).

Recebido em 29 de maio de 2001

A provado em 12 de dezembro de 2002

Márcio Caniello é professor do Departamento de Sociologia e A ntropologia e do Programa de Pós-Graduação em Sociologia (PPGS) da Universidade Federal de Campina Grande (UFCG), onde trabalha desde 1986. Mestre em Antropologia Social pelo PPGAS/MN/UFRJ (1993) e doutor em Sociologia pela Universidade Federal de Pernambuco (2001), atualmente é coordenador do PPGS/UFCG e membro da diretoria da ANPOCS. 


\section{Notas}

* Este artigo foi escrito originalmente em 1998 para uma col etânea que deveria registrar os desdobramentos do prolífico debate iniciado no seminário "Estrutura e Relações de Poder" ministrado pelos profs. M oacir Palmeira e Beatriz Heredia, em 1989 no Museu Nacional. Malogrado o projeto e mantido o ineditismo do artigo, os organizadores do livro gentilmente encaminharam o texto à consideração da editoria da Revista M ana, que, agora, o publica com modificações substanciais em relação à versão inicial, fruto das sugestões e críticas de dois pareceristas anônimos de $\mathrm{M}$ ana, aos quais agradeço.

1 “Ou nossas ciências se vinculam à dimensão diacrônica dos fenômenos, isto é, à sua ordem no tempo, e se tornam incapazes de traçar-Ihes a história; ou procuram trabalhar à maneira do historiador e a dimensão do tempo Ihes escapa" (Lévi-Strauss 1975:15).

2 Refiro-me à dissertação de M estrado defendida no M useu N acional (Caniello 1993) e à tese de Doutorado defendida no Programa de Pós-Graduação em Sociologia da UFPE (Caniello 2001). A gradeço as críticas, sugestões e estímulo dos profs. Roberto DaM atta, orientador da dissertação de M estrado e examinador da tese de Doutorado, J orge Ventura de M orais, orientador da tese de Doutorado, M oacir Palmeira e Otávio Guilherme Velho, examinadores da dissertação de M estrado, e Salete Barbosa Cavalcanti, M arcus Carvalho e Socorro Ferraz, examinadores da tese de Doutorado.

3 Sobre o conceito de “modulação”, cf. Caniello (1990a; 1993:300-301).

4 Aqui, estou admitindo a interpretação de Roberto DaM atta (1993:19-21) sobre a distinção entre "holismo e individualismo" proposta por Louis Dumont (1985:37; 1992:56-59). Para um detalhamento de minha posição em relação a estes conceitos e interpretações, cf. Caniello (1993:11-13).

5 Em outro trabalho, analisei as repercussões teóricas e os paradoxos do uso da noção de "mudança social" nos "estudos de comunidade" (cf. Caniello 1990b).

6 Denominação dos chefes do Executivo municipal na República Velha, equivalente ao de prefeito atualmente.

7 Nesse período, havia "dissidências" nos dois principais partidos republicanos estaduais (o paulista e o mineiro, que mantinham sua hegemonia política no Brasil através da "política do café-com-leite"). Seu discurso contra a "política dos governadores" e as "oligarquias" - base do federalismo na República VeIha - , prefigurava o embate que transformaria o modelo político brasileiro, a Revolução de 30 (cf. Casalecchi 1987:100, passim). 
8 Cf. Freyre (1994 [1933]:28 e 72), para uma elaboração clássica e paradigmática dessa idéia (cf. Caniello 2001:346, passim). Para uma visão contemporânea, cf. Palmeira e Heredia (1997:160): “N ossa sociedade revela-se atravessada por conflitos de toda ordem, mas, num paradoxo aparente, tem na união - de que a família, não o grupo doméstico na sua crua realidade, é o melhor exemplo uma espécie de valor maior".

9 Utilizei intensamente a noção de "padrão ético" em vários trabalhos (cf., esp., Caniello 1990a; 1993, passim).

${ }^{10}$ A credito que esse é um arranjo estrutural bastante homólogo ao que Geert identificou nos diversos "planos de organização social" em Tihingan (cf. Geertz 1967:272).

11 J ustino Filho (1997) identifica o mesmo processo em um estudo de caso sobre a história sociopolítica da cidade de Princesa Isabel (PB), chamando-o de “ressignificação".

\section{Referências bibliográficas}

ABREU, Marcelo de Paiva. 1984. “O Brasil e a Economia Mundial". In: B. Fausto (org.), O Brasil Republicano: Economia e Cultura (1930-1964). São Paulo: Difel (História Geral da Civilização Brasileira, tomo III, vol. 4). pp. 9-49.

ALEXANDER, J effrey. 1987. “O Novo M ovimento Teórico". Revista Brasileira de Ciências Sociais, 2(4):5-28.

. 1990. Action and its Environments: Toward a New Synthesis. New York: New York University Press.

ARISTÓTELES. 1973. “Ética a Nicômaco"

(Trad. de Leonel Vallandro e Gerd Bornheim). In: J. A. M. Pessanha (org.), A ristóteles. São Paulo: A bril
Cultural (Os Pensadores). pp. 245436.

CAMARGO, Aspásia de Alcântara. 1983.

“A Questão Agrária: Crise de Poder e Reformas de Base". In: B. Fausto (org.), O Brasil Republicano: Sociedade e Política. São Paulo: Difel (História Geral da Civilização Brasileira, tomo III, vol. 3). pp. 121-224.

CANIELLO, Márcio. 1990a. “Patronagem e Rivalidade: Observações Iniciais sobre Processos de Modulação Ética numa Cidade do Interior". Revista Brasileira de Ciências Sociais, 5(14):46-58.

. 1990b. Os Estudos de Comunidade no Brasil: Algumas Reflexões so- 
bre a Noção de Mudança Social. Trabalho de final de curso apresentado ao prof. Luís de Castro Faria. Rio de J aneiro. Manuscrito.

. 1993. Sociabilidade e Padrão Ético numa Cidade do Interior: Carnaval, Política e Vida Cotidiana em São J oão Nepomuceno - MG. Dissertação de M estrado, PPGAS/M useu $\mathrm{N}$ acional/UFRJ , Rio de J aneiro. .2001. O Ethos Brasílico: Sociologia Histórica da Formação Nacional (1500-1654). Tese de Doutorado, PPGS/UFPE, Recife.

e SOÁREZ, Elena. 1989. As Relações de A mizade em São J oão N epomuceno. Relatório de Pesquisa, PPGAS/M useu Nacional/UFRJ, Rio de J aneiro. Manuscrito.

CARONE, Edgar. 1978. A Segunda República (1930-1937) (3ạ ed.). São Paulo: Difel (Corpo e Alma do Brasil, vol. XXXVII).

CASALECCHI, J osé Ênio. 1987. O Partido Republicano Paulista: Política e Poder (1889-1926). São Paulo: Brasiliense.

CASTRO, Celso Falabella de Figueiredo. 1987. Os Sertões do Leste: Achegas para a História da Zona da Mata. Belo Horizonte: Imprensa Oficial.

DAMATTA, Roberto. 1983. Carnavais, M alandros e Heróis: Para uma Sociologia do Dilema Brasileiro (4a ed.). Rio de J aneiro: Zahar.

. 1986. O que Faz o Brasil, Brasil? Rio de J aneiro: Rocco.

. 1987. A Casa \& a Rua: Espaço, Cidadania, Mulher e M orte no Brasil. Rio de J aneiro: Guanabara.

. 1993. Conta de Mentiroso: Sete Ensaios de Antropologia Brasileira. Rio de J aneiro: Rocco.

DUM ONT, Louis. 1985. Individualismo: Uma Perspectiva A ntropológica da I deologia M oderna (Trad. de Álvaro Cabral). Rio de J aneiro: Rocco.
. 1992. Homo Hierarchicus: O Sistema de Castas na Índia. São Paulo, Editora da USP.

ELIAS, N orbert. 1994. A Sociedade dos Indivíduos (Trad. de Vera Ribeiro). Rio de J aneiro: J orge Zahar.

FAUSTO, Boris. 1990. “A Revolução de 1930". In: C. G. M ota (org.), Brasil em Perspectiva (19a ed.). São Paulo: Bertrand Brasil (Corpo e Alma do Brasil, vol. XXIII). pp. 227-255.

FERNANDES, Florestan. 1987. A Revolução Burguesa no Brasil: Ensaio de Interpretação Sociológica (3a ed.). Rio de J aneiro: Guanabara.

FREYRE, Gilberto. 1994 [1933]. CasaGrande \& Senzala: Formação da Família Brasileira sob o Regime da Economia Patriarcal (29a ed.). Rio de J aneiro: Record.

GEERTZ, Clifford. 1967. “Form and Variation in Balinese Village Structure". In: J. Potter (org.), Peasant Society: A Reader. Boston: Little Brown. pp. 255-278.

. 1978[1973]. A Interpretação das Culturas (Trad. de Fanny Wrobel). Rio de J aneiro: Zahar.

GIDDENS, Anthony. 1989. A Constituição da Sociedade (Trad. de Álvaro Cabral). São Paulo: Martins Fontes. HEGEL, Georg Wilhelm Friedrich. 1982 [1837]. Lecciones sobre la Filosofía de la Historia Universal (Trad. de J osé Gaos). Madrid: Alianza Editorial.

HOLANDA, Sérgio Buarque de. 1988 [1936]. Raízes do Brasil (20a ed.). Rio de J aneiro: J osé Olympio (C oleção Documentos Brasileiros, vol. 1).

HYPPOLITE, J ean. 1983. Introduction à la Philosophie de l'Histoire de $\mathrm{Hegel}$. Paris: Éditions de Seuil.

INWOOD, Michael. 1997. Dicionário Hegel (Trad. de Álvaro Cabral). Rio de J aneiro: J orge Zahar Editor (Dicionários de Filósofos). 
JOTA EFEGÊ (J oão Ferreira Gomes). 1982. Figuras e Coisas do Carnaval Carioca. Rio de J aneiro: Funarte.

JUSTINO FILHO, J osé. 1997. A Tradição Ressignificada: Uma Leitura da Vida Sócio-Política de Princesa Isabel - PB. Dissertação de M estrado em Sociologia, UFPB, Campina Grande.

KROEBER, A. L. 1963 [1923]. Anthropology: Culture, Patterns and Processes. New York: Harcourt, Brace \& World, Inc.

LANDÉ, Carl. 1977. “The Dyadic Basis of Clientelism". In: S. W. Schmidt (org.), Friends, Followers and Factions. Berkeley: University of California Press. pp. xiii-xxxvii.

LEAL, Victor N unes. 1986. Coronelismo, Enxada e Voto: O M unicípio e o Regime Representativo no Brasil (5a ed.). São Paulo: Alfa-Ômega.

LÉVI-STRAUSS, Claude. 1975. Antropologia Estrutural (Trad. de Chaim Samuel Katz e Eginardo Pires). Rio de J aneiro: Tempo Brasileiro. .1976[1962]. O Pensamento Selvagem. São Paulo: Companhia Editora Nacional.

PALMEIRA, Moacir e HEREDIA, Beatriz. 1997. "Política Ambígua". In: P. Birman, R. Novaes e S. Crespo (orgs.), $\mathrm{O} \mathrm{M}$ al à Brasileira. Rio de J aneiro: EDUERJ .

PRADO, Rosane M anhães. 1987. Mulher de Novela, Mulher de Verdade: Estudo sobre Cidade Pequena, M ulher e Telenovela. Dissertação de M estrado, PPGAS/M useu Nacional/UFRJ , Rio de J aneiro.

QUEIROZ, Maria Isaura Pereira de. 1977. “O Coronelismo numa Interpretação Sociológica". In: B. Fausto (org.), O Brasil Republicano: Estrutura de Poder e Economia (18891930) (2a ed.). São Paulo: Difel (História Geral da Civilização Brasileira, tomo III, vol. 1). pp. 153-190.
SAHLINS, Marshall. 1990. Il has de História (Trad. de Bárbara Sette). Rio de J aneiro: J orge Zahar Editor.

SARTRE, J ean Paul. 1960. Critique de la Raison Dialectique. Paris: Gallimard. SCOTT, J ames. 1969. "Corruption, Machine Politics, and Political Change". The American Political Science Review, 63(4):1142-1158.

SEBE, J osé Carlos. 1986. Carnaval, Carnavais. São Paulo: Ática (Princípios, 65).

SINGER, Paul. 1984. “Interpretação do Brasil: Uma Experiência Histórica de Desenvolvimento". In: B. Fausto (org.), O Brasil Republicano: Economia e Cultura (1930-1964). São PauIo: Difel (História Geral da Civilização Brasileira, tomo III, vol. 4). pp. 209-245.

SKIDM ORE, Thomas. 1982. Brasil: De Getúlio Vargas a Castelo Branco (19301964) (Trad. de Ismênia Tunes Dantas) (7ạ ed.). Rio de J aneiro: Paz e Terra.

SODRÉ, Nelson Werneck. 1963. Formação Histórica do Brasil (2a ed.). São Paulo: Brasiliense.

VERGNIÈRES, Solange. 1999. Ética e Política em A ristóteles: Physis, Ethos, Nomos (Trad. de Constança Marcondes César). São Paulo: Paulus (Ensaios Filosóficos).

Weber, Max. 1987. A Ética Protestante e o Espírito do Capitalismo (Trad. de M. Irene de Q. F. Szmrecsányi e Tamás J . M. K. Szmrecsányi). São Paulo: Pioneira (Biblioteca Pioneira de Ciências Sociais. Sociologia).

\section{Jornais}

A Cruzada. A nos I-V, no 2-216. São J oão Nepomuceno, 1926-1930.

Voz do Povo. A nos I-XXX, no 1-1.452. São J oão Nepomuceno, 1907-1937. Voz de São J oão. Anos I-LIV, no 1-2.718. São J oão Nepomuceno, 1937-1990. 
Resumo

Este artigo analisa como o "padrão pessoalizante de relações sociais", arquetípico das chamadas sociedades holistas ou tradicionais, âmago do ethos nacional brasileiro e elemento estruturante da vida coletiva nas "cidades pequenas", reage diante do "processo de individualização" provocado pela expansão do capitalismo e de seus valores dominantes. Tomando como referência o período em que o Brasil passou a se incluir mais vigorosamente sob a "ordem social competitiva" do sistema mundial, o texto reconstitui a história do faccionalismo - uma expressão proeminente do padrão pessoalizante de relações sociais - em uma pequena cidade de Minas Gerais entre o final do século XIX e o final do século $X X$. $O$ objetivo é relativizar a concepção de que esse processo tenha redundado em uma decaída do estilo de vida tradicional da pequena cidade, mas também rejeitar a idéia de que a tradição se mantém incólume à passagem do tempo, propondo que a dialética entre tradição e mudança explicita "processos de modulação" do ethos local.

Palavras-chave Ethos, Faccionalismo, Tradição e Mudança

\section{Abstract}

This article analyzes how the 'personalizing pattern of social relations' archetypical of so-called holistic or traditional societies - the core of the Brazilian national ethos and a structuring element of the collective life in 'small towns' - has responded to the 'individualization process' provoked by the expansion of capitalism and its dominant values. Taking as its context the period during which Brazil inserted itself ever more forcibly into the competitive social order of the world system, the text reconstructs the history of factionalism - a prominent expressive feature of the personalizing pattern of social relations - in a small town of M inas Gerais between the ends of the 19th and 20th centuries. The aim is to relativize the conception that this process has led to a decline in the traditional lifestyle of the small town, but also to reject the idea that tradition continues unscathed by the passage of time, proposing instead that the dialectic between tradition and change makes explicit various modulation processes of the local ethos.

Key w ords Ethos, Faccionalism, Tradition and Change 